Article

\title{
A Metabolomic and HPLC-MS/MS Analysis of the Foliar Phenolics, Flavonoids and Coumarins of the Fraxinus Species Resistant and Susceptible to Emerald Ash Borer
}

\author{
Sohail S. Qazi ${ }^{1,2}$, Domenic A. Lombardo ${ }^{1}$ and Mamdouh M. Abou-Zaid ${ }^{1,2, *}$ \\ 1 Natural Resources Canada, Canadian Forest Service, Great Lake Forestry Centre, \\ Sault Ste. Marie, ON P6A 2E5, Canada; soq823@mail.usask.ca (S.S.Q.); \\ domenic.lombardo@canada.ca (D.A.L.) \\ 2 Department of Chemical and Biochemical Engineering, University of Western Ontario, \\ London, ON N6A 5B9, Canada \\ * Correspondence: mamdouh.abouzaid@canada.ca; Tel.: +1-705-541-5523; Fax: +1-705-541-5700
}

Received: 4 October 2018; Accepted: 20 October 2018; Published: 23 October 2018

check for updates

\begin{abstract}
The Emerald Ash Borer (EAB), Agrilus planipennis, Fairmaire, an Asian invasive alien buprestid has devastated tens of millions of ash trees (Fraxinus spp.) in North America. Foliar phytochemicals of the genus Fraxinus (Oleaceae): Fraxinus pennsylvanica (Green ash), F. americana (White ash), F. profunda (Bush) Bush. (Pumpkin ash), F. quadrangulata Michx. (Blue ash), F. nigra Marsh. (Black ash) and F. mandshurica (Manchurian ash) were investigated using HPLC-MS/MS and untargeted metabolomics. HPLC-MS/MS help identified 26 compounds, including phenolics, flavonoids and coumarins in varying amounts. Hydroxycoumarins, esculetin, esculin, fraxetin, fraxin, fraxidin and scopoletin were isolated from blue, black and Manchurian ashes. High-throughput metabolomics revealed 35 metabolites, including terpenes, secoiridoids and lignans. Metabolomic profiling indicated several upregulated putative compounds from Manchurian ash, especially fraxinol, ligstroside, oleuropin, matairesinol, pinoresinol glucoside, 8-hydroxypinoresinol-4-glucoside, verbenalin, hydroxytyrosol-1-O-glucoside, totarol and ar-artemisene. Further, dicyclomine, aphidicolin, parthenolide, famciclovir, ar-turmerone and myriocin were identified upregulated in blue ash. Principal component analysis demonstrated a clear separation between Manchurian and blue ashes from black, green, white and pumpkin ashes. The presence of defensive compounds upregulated in Manchurian ash, suggests their potential role in providing constitutive resistance to $\mathrm{EAB}$, and reflects its co-evolutionary history with A. planipennis, where they appear to coexist in their native habitats.
\end{abstract}

Keywords: Emerald Ash Borer (Agrilus planipennis); HPLC-MS/MS; metabolomics; Fraxinus spp. phenolics; flavonoids; coumarins; lignans; secoiridoids; invasive species

\section{Introduction}

The Emerald Ash borer (EAB), Agrilus planipennis Fairmaire (Coleoptera: Buprestidae) is an invasive wood-borer indigenous to Asia that has caused widespread mortality of North American ash (Fraxinus spp.) [1]. Since its accidental introduction in North America, that can be traced back to 1990 [2], EAB infestations have been identified in twenty-five American states and two Canadian provinces. EAB larvae feed from spring to mid-summer on the phloem and outer xylem tissue, which disrupt the translocation of nutrients and water that results in the ultimate death of the tree. EAB adults emerge from larval hosts and complete one to two weeks of feeding on ash foliage before they become 
reproductively mature. In the majority of cases, ash trees are killed within six years of EAB infestation or detection [1].

The Genus Fraxinus (Oleaceae, Olive family) has sixty species, of which sixteen of them are native to North America, and amongst them four species are native to Canada [3]. In North America, the EAB is a major invasive pest threatening all of the North American species, including Fraxinus pennsylvanica var. subintegerrima (Vahl) Fern. (Green ash), F. americana L. (White ash), F. pennsylvanica Marsh. (Red ash), F. pennsylvanica var. austini Fern. (Northern red ash), F. nigra Marsh. (black ash) [1,4-6]. F. profunda Bush. (Pumpkin ash) and F. latifolia Benth. (Oregon ash) ashes have been reported as being seldomly attacked by EAB. However, F. quadrangulata Michx. (blue ash) has been reported to be somewhat resistant in comparison to green and white ashes, especially where they co-occur $[7,8]$. The economic and ecological impact of EAB damage is enormous and has prompted the International Union for Conservation of Nature (IUCN) to put several ash species on their watch list of critically endangered species [9], including blue ash. The economic impact of EAB in North America is in the order of billions of dollars [10,11]. On the other hand, F. mandshurica (Manchurian ash), which is the preferred host of EAB in China is resistant to EAB infestation, because of its co-evolutionary history.

The chemistry of the genus Fraxinus is highly complex [12] and the defensive response of deciduous trees to wood-boring beetle attacks has been postulated to be a combination of constitutive and induced physical and chemical defenses [13]. In this connection, studies to date on the Fraxinus spp. has focused on the chemistry of the phloem and bark tissue, especially on clonal cultivars (greenhouse studies) of ash species. The phloem chemistry of the Manchurian, white and green ashes revealed phenolic compounds, including monolignols, lignans, phenylethanoids and secoiridoids [14]. Hydroxycoumarins and phenylethanoids (calceolariosides A and B) were identified unique to Manchurian ash. Similarly, Cipollini and co-workers investigated the distinguishing defensive compounds from the phloem of the Manchurian ash and have identified unique contents of hydroxycoumarins (fraxin, mandshurin and fraxidin hexoside) [15]. In addition, they reported phenylethanoids (calceolariosides A and B) and significantly higher concentrations of the lignans (pinoresinol glucoside and pinoresinol) from Manchurian ash. The lignans in the genus Fraxinus are mainly of tetrahydrofurofuran or sesamine type $[16,17]$ and are found in their free or glycosidic forms [12].

During an investigation on the defensive chemical response of Manchurian ash the presence of phenolics, including hydroxycoumarins and phenylethanoid glycosides (calceolariosides A and B), pinoresinol (a dihexoside) and a coumarin derivative unique to Manchurian ash were reported [18]. Furthermore, high concentration levels of esculin (hydroxycoumarin), responsible for the greater resistance of Manchurian ash relative to other North American ash species was identified [18]. On the other hand, higher accumulations of lignan (pinoresinol A) in the phloem of Manchurian ash in contrast to black ash was documented during the induced resistance from EAB [19].

Ironically, to date, the foliar chemistry of North American ash has received little or no attention, despite its importance in EAB biology, as the foliage is the only source of maturation feeding for adult EAB. This study aims to investigate the metabolomic composition of six Fraxinus spp. (green, Manchurian, blue, black, pumpkin and white ashes) using HPLC-MS/MS and untargeted metabolomics. In addition, we have provided a comparison of metabolites between Manchurian and blue ashes that have varying levels of resistance to EAB. To the best of our knowledge, this study represents the first report using HPLC-MS/MS combined with autonomous untargeted metabolomic profiling in examining the foliar chemistry of six Fraxinus spp. and in describing the potential role that defensive polyphenolic compounds may play in providing resistance to EAB. 


\section{Results and Discussion}

\subsection{HPLC-MS/MS Orbitrap Analysis}

Because of the intricate nature of the foliar chemistry of the genus Fraxinus, the use of HPLC-MS/MS and autonomous untargeted metabolomics provided the necessary means for investigating the issue. In this study, hydroxycoumarin, phenolic, flavonol, flavanol, flavone and flavanone variations in the leaves of the six Fraxinus spp. (green, Manchurian, blue, black, pumpkin and white ashes) compounds were identified using HPLC-MS/MS (Figure 1). A list of 26 compounds and their characterization based on compound classes are presented in Table 1. Spectral analysis and chromatography with standards were used for compound identification. In addition, NMR spectroscopy was employed for the structural elucidation of the isolated compounds. Chemical structures of some of the major compounds identified in this study can be appreciated from the Figure 2. A complete list of the compounds (1-26) with confirmed identities by NMR is presented in Table 1.

Six hydroxycoumarins have been identified (Table 1) from blue, black and Manchurian ashes in varying amounts, as indicated by percentage peak areas. Esculin was identified in 3-fold high concentration from blue and black ashes in contrast to Manchurian ash. High levels of esculin have also been reported from blue ash [18]. Esculetin was identified in 4-fold high concentration in Manchurian ash in contrast to blue and black ashes. In addition, the compound fraxin was identified in high amounts (8.4 and 1.3-fold, respectively) in Manchurian ash than in blue and black ashes. Similarly, high concentrations of fraxin were reported from Manchurian ash [18]. Fraxetin was identified in high amounts (2.0 and 1.4-fold, respectively) from Manchurian ash in comparison with blue and black ashes. In a previous study, fraxetin was only reported from black ash [18]. High amounts (9 and 3-fold, respectively) of fraxidin was identified from blue ash in contrast to black and Manchurian ashes. In addition, scopoletin was identified in significantly higher concentrations (2.0 5.0, 77 and 86-fold, respectively) from blue ash in comparison to Manchurian, black, pumpkin and white ashes. Scopoletin has been documented as an effective anti-feeding compound against the sunflower beetle and termites [20,21]. Coumarins have also been well documented as contributing to the resistance factor against EAB. In a similar vein, higher concentrations of coumarins were identified from the phloem tissue of Manchurian ash in comparison to black and European ashes [14,15], suggesting these compounds could potentially act as determinants of resistance. In contrast, Whitehill and co-workers reported contrasting results and documented the presence of coumarins from the phloem of black and European ashes in amounts, comparable to or higher than Manchurian ash, implying they are not the determinants of resistance [18].

During this investigation, phenolics and phenolic acids were identified from the leaves of six Fraxinus spp. (Table 1) in varying amounts. Amongst phenolics, caffeic, ferulic and p-coumaric acids were reported from F. americana and F. excelsior [22,23]. Furthermore, we identified additional flavonoids and flavonoid glycosides from the six species of Fraxinus. Flavones and flavonols have been documented as characteristic compounds for the genus Fraxinus [12]. Kaempferol and kaempferol glycosides were identified (Table 1) with varying levels from the leaves of the six Fraxinus spp. Similarly, three flavonols, kaempferol-3-O- $\beta$-D-glucopyranoside, kaempferol-3-O- $\alpha$-L-rhamnopyranosyl- $(1 \rightarrow 6)-\beta$-D-glucopyranoside and quercetin-3-O- $\alpha$ - L-rhamnopyranosyl $-(1 \rightarrow 6)-\beta$-D-glucopyranoside were identified from the leaves of F. oxycarba [24]. Furthermore, kaempferol-3-O-rutinoside was also identified from the leaves of Fraxinus angustifolia (Vahl) [25].

Kaempferol 3-O-(6-O- $\alpha$-L-rhamnopyranosyl- $\beta$-D-galactopyranoside), kaempferol 3-O-(6-O- $\alpha$ -L-rhamnopyranosyl- $\beta$-D-glucopyranoside), and kaempferol 7-O-(2-O- $\alpha$-L-rhamnopyranosyl- $\beta$ -D-glucopyranoside) were previously reported from F. americana [26]. Kaempferol glycoside and quercetin have also been reported from F. excelsior [27]. On the other hand, kaempferol galactoside was identified from the phloem of F. excelsior [18]. Isoquercetrin (quercetin 3-O-glucoside) and rutin (quercetin 3-O- $\alpha$-L-rhamnopyranosyl-1-6-glucopyranose) have been identified from the leaves of Fraxinus angustifolia 
(Vahl) [25]. Interestingly, we identified the flavanone, naringenin not previously reported from the green ash. Phenolic compounds, a characteristics of the genus Fraxinus may have the potential to act as feeding deterrents, toxins and digestion inhibitors [21,28,29].
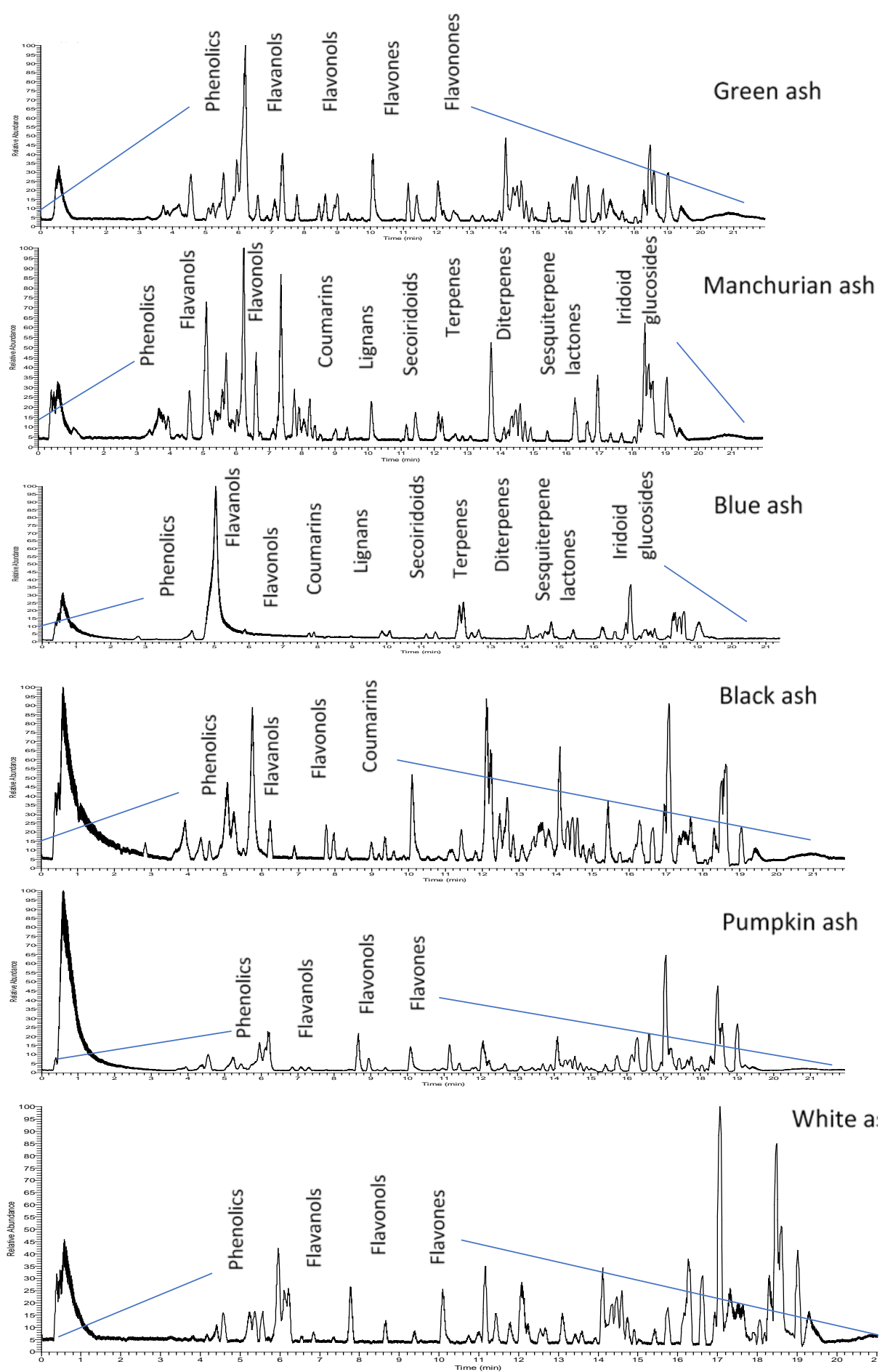

Figure 1. Representative HPLC-MS/MS base peak chromatograms of foliar extracts from six Fraxinus spp. (green, Manchurian, blue, black, pumpkin, and white ashes), revealing the diversity of separated compounds. 
Table 1. HPLC-MS/MS analysis used for the identification of compounds from blue, Manchurian, black, green, pumpkin, and white ashes. Actual mass, M + H, RT, and percentage peak areas among reported compounds.

\begin{tabular}{|c|c|c|c|c|c|c|c|c|c|c|}
\hline \multirow{3}{*}{ No } & & & & & Dipetalae & Fraxinu & & & Melioides & \\
\hline & \multicolumn{10}{|l|}{ Compound Name } \\
\hline & & Actual Mass & $\mathbf{M}+\mathbf{H}$ & RT & Blue Ash & Manchurian Ash & Black Ash & Green Ash & Pumpkin Ash & White Ash \\
\hline & Coumarins & & & & & & & & & \\
\hline 1 & Esculin & 340.284 & 341.0857 & 2.8 & 0.31 & 0.12 & 0.37 & N.D. & N.D. & N.D. \\
\hline 2 & Esculetin & 178.143 & 179.0335 & 3.55 & 0.07 & 0.32 & 0.08 & N.D. & N.D. & N.D. \\
\hline 3 & Fraxetin & 208.169 & 209.0439 & 4.2 & 0.11 & 0.21 & 0.15 & N.D. & N.D. & N.D. \\
\hline 4 & Fraxidin & 222.196 & 223.0595 & 5.64 & 0.46 & 0.17 & 0.05 & N.D. & N.D. & N.D. \\
\hline 5 & Fraxin & 370.310 & 371.0962 & 5.7 & 0.05 & 0.42 & 0.32 & N.D. & N.D. & N.D. \\
\hline \multirow[t]{2}{*}{6} & Scopoletin & 192.170 & 193.0492 & 5.0 & 6.89 & 3.09 & 1.37 & N.D. & 0.09 & 0.08 \\
\hline & Phenolics/Phenolic Acids & & & & & & & & & \\
\hline 7 & Chlorogenic acid & 354.311 & 355.1018 & 3.5 & 0.08 & 0.13 & 0.07 & 0.04 & 0.06 & 0.17 \\
\hline 8 & Caffeic acid & 180.159 & 181.0496 & 3.7 & 0.08 & 0.58 & N.D. & N.D. & N.D. & N.D. \\
\hline 9 & Syringic acid & 198.174 & 199.0601 & 3.9 & 0.04 & 0.07 & N.D. & N.D. & N.D. & N.D. \\
\hline 10 & Ferulic acid & 194.186 & 195.0651 & 5.2 & 0.84 & N.D. & N.D. & N.D. & N.D. & N.D. \\
\hline 11 & $p$-Coumaric acid & 164.160 & 165.0546 & 4.8 & 0.79 & 0.1 & 0.08 & N.D. & 0.04 & 0.04 \\
\hline 12 & $\begin{array}{l}\text { Gentisic acid } \\
\text { Flavanols }\end{array}$ & 154.121 & 155.0338 & 5.74 & 0.24 & N.D. & N.D. & N.D. & N.D. & N.D. \\
\hline 13 & $(+)$ Catechin & 290.271 & 291.0859 & 10.0 & 0.15 & 0.04 & 0.02 & 0.18 & 0.01 & 0.03 \\
\hline 14 & $\begin{array}{l}(-) \text {-Epicatechin } \\
\text { Flavones }\end{array}$ & 290.271 & 291.0859 & 15.3 & 0.09 & 0.12 & 0.06 & 0.15 & 0.01 & 0.09 \\
\hline 15 & Apigenin & 270.240 & 271.0597 & 8.6 & N.D. & N.D. & N.D. & 0.68 & 0.18 & N.D. \\
\hline 16 & Luteolin & 286.239 & 287.0545 & 7.7 & N.D. & N.D. & N.D. & 0.1 & 0.05 & N.D. \\
\hline 17 & Luteolin-7-O-glucoside & 448.380 & 449.1068 & 5.5 & N.D. & 0.89 & N.D. & 1.4 & 0.17 & 0.16 \\
\hline 18 & $\begin{array}{l}\text { Luteolin-3',7-O- } \beta \text {-D-diglucoside } \\
\text { Flavonols }\end{array}$ & 610.518 & 611.1589 & 4.9 & N.D. & N.D. & N.D. & 0.04 & 0.02 & 0.21 \\
\hline 19 & Quercetin-3-O- $\beta$-D-glucoside & 464.379 & 465.1018 & 5.6 & 0.57 & 0.35 & 0.1 & 0.37 & 0.11 & 0.84 \\
\hline 20 & Quercetin-3-O- $\beta$-D-galactoside & 464.379 & 465.1018 & 5.48 & N.D. & 0.64 & 0.28 & 0.03 & 0.1 & 0.04 \\
\hline 21 & Quercetin-3-O- $\beta$-L-rhamnoside & 448.380 & 449.1068 & 6.14 & 0.14 & 1.1 & 0.13 & 3.32 & 0.68 & 1.0 \\
\hline 22 & Quercetin-3-O-rhamnoglucoside & 610.521 & 611.1589 & 5.4 & 0.34 & 0.15 & 0.2 & N.D. & 0.34 & 0.86 \\
\hline 23 & Kaempferol-3-O- $\beta$-D-glucoside & 448.380 & 449.1070 & 6.08 & 0.26 & 0.07 & 0.1 & N.D. & N.D. & 0.13 \\
\hline 24 & $\begin{array}{l}\text { Kaempferol-3-O-rhamnoglucoside } \\
\text { Kaempferol-2-B-coumaryl }\end{array}$ & 594.522 & 595.1643 & 5.9 & N.D. & 0.3 & 0.32 & N.D. & 0.3 & 0.2 \\
\hline 25 & $\begin{array}{l}\text { glucoside } \\
\text { Flavanone }\end{array}$ & 594.525 & 595.1432 & 7.8 & N.D. & N.D. & N.D. & N.D. & 0.06 & N.D. \\
\hline 26 & Naringenin & 272.257 & 273.0752 & 8.4 & N.D. & N.D. & N.D. & 0.51 & N.D. & N.D. \\
\hline
\end{tabular}

N.D. Not detected. Compounds (1-26) were identified using authentic standards. Identities of the compounds (1-26) were confirmed by NMR. 
<smiles>O=c1ccc2cc(O)c(O)cc2o1</smiles>

Esculetin<smiles>COc1cc2ccc(=O)oc2c(O)c1O</smiles>

Fraxetin<smiles>O=c1ccc2cc(O[AlH2])c(O)cc2o1</smiles>

Esculin<smiles>COc1cc2ccc(=O)oc2c(O)c1OC</smiles>

Fraxidin<smiles>COc1cc2ccc(=O)oc2c(O)c1O</smiles>

(a)

$$
\text { Fraxin }
$$

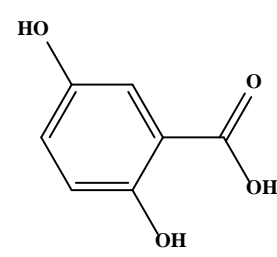

Gentisic Acid

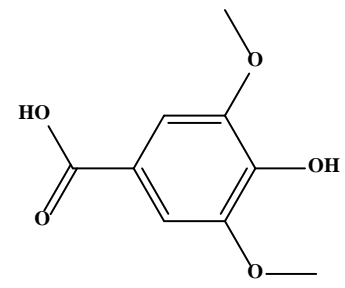

Syringic acid

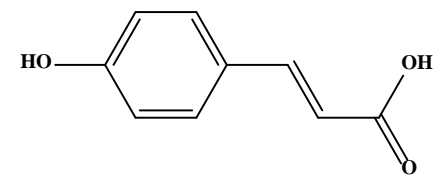

p-Coumaric acid

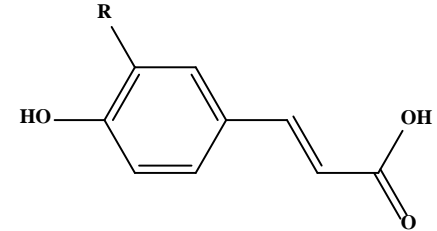

$\mathbf{R}=\mathbf{O H} \quad$ Caffeic acid $\mathbf{R}=\mathbf{O C H}_{3}$ Ferulic acid<smiles>O=C(/C=C/c1ccc(O)c(O)c1)O[C@H]1C[C@H](O)[C@@H](O)C[C@](O)(C(=O)O)C1</smiles>

Chlorogenic acid

(b)

Figure 2. Cont. 
<smiles>Oc1cc(O)c2c(c1)O[C@@H](c1ccc(O)c(O)c1)CC2</smiles><smiles>Oc1cc(O)c2c(c1)O[C@H](c1ccc(O)c(O)c1)[C@H](O)C2</smiles>

(c)

(-)-Epicatechin

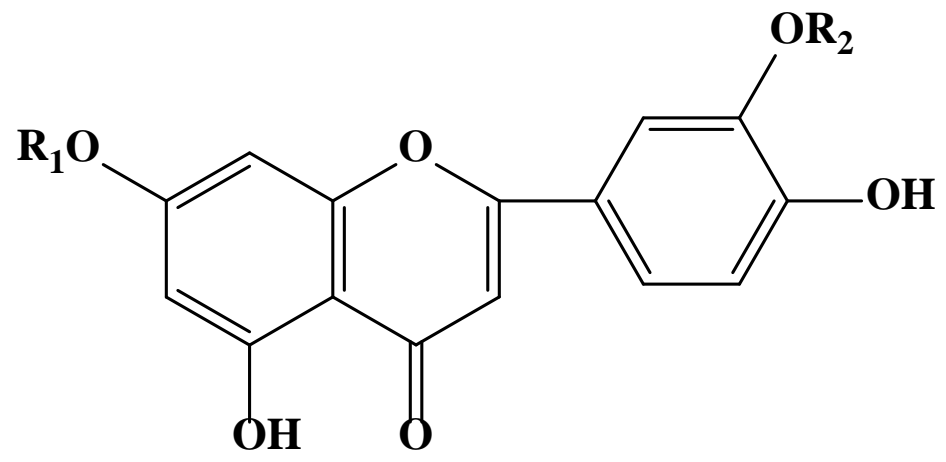

$$
\mathbf{R}_{1}={ }_{H}, R_{2}=H \quad \text { Luteolin }
$$

$\mathbf{R}_{\mathbf{1}}=$ glucosylglucosyl, $\mathrm{R} 2=\mathrm{H} \quad$ Luteolin 7-O-glucoside (d)

$\mathbf{R}_{1}=$ glucosyl, $\mathbf{R}_{2}=$ glucosyl Luteolin 3',7-O-diglucoside

Figure 2. Cont. 
<smiles>[R]Oc1c(-c2ccc(O)c([R1])c2)oc2cc(O)cc(O)c2c1=O</smiles>

\author{
$\mathbf{R}=$ glucosyl, $\mathbf{R}_{\mathbf{1}}=\mathbf{H}$ \\ Kaempferol ${ }^{3-O^{-}}$glucoside \\ $\mathrm{R}=$ galactosylosyl, $\mathrm{R}_{\mathbf{1}}=\mathrm{H} \quad$ Kaempferol ${ }^{3-\mathrm{O}^{-}}$galacotoside \\ $\mathrm{R}=$ glucosyl, $\mathrm{R}_{\mathbf{1}}=\mathbf{O H}$ \\ Quercetin ${ }^{3-\mathrm{O}^{-}}$glucoside \\ $\mathrm{R}=$ rhamnosyl, $\mathrm{R}_{\mathbf{1}}=\mathrm{OH}$ \\ Quercetin 3-O'- rhamnoside
}

\title{
(e) $\mathrm{R}=$ rhamnoglucosyl, $\mathrm{R}_{1}=\mathrm{OH}$ Quercetin $3-\mathrm{O}^{-}$rhamnoglucosyl
}

Figure 2. (a-e). Chemical structures of coumarins (a), phenolics (b), flavanols (c), flavones (d), and flavonols (e) isolated and purified from green and blues ashes.

\subsection{Metabolomic Analysis of Fraxinus spp.}

To better understand the complexity of foliar chemistry in the six Fraxinus spp. (green, Manchurian, blue, black, pumpkin and white ashes), the metabolomics approach was adopted. In the past, metabolomics received little attention regarding the genus Fraxinus, and only two investigations focused on F. excelsior [30,31]. During metabolomic analysis, the autonomous untargeted metabolomics approach provided a global picture of the metabolites from the leaves of six Fraxinus spp. The multigroup comparison (Figure 3) revealed in the heat map (dendrogram), demonstrated that the six species of the genus Fraxinus clustered into six groups, implying the influence of metabolite features of each species with high clustering coefficient. The untargeted metabolic profiling and metadata analysis resulted in the detection of 1000 metabolite features $(p<0.00001)$ from the six Fraxinus spp. The heat map is significant in that it has the unique ability to identify clusters of samples with similar metabolic patterns and discriminating metabolites, which can facilitate sample clustering [32]. The interactive metabolic cloud plot generated (data not presented) during the multi-group analysis revealed that the majority of the metabolite features $(p<0.00001)$ were upregulated in Manchurian ash in contrast to other species. The metabolomic cloud map allowed the detection of metabolite features (based on retention times and $m / z$ ratios), whose levels differ between different groups $(p<0.00001)$. Overall, the autonomous untargeted metabolomic approach of the XCMS bioinformatics platform provided an efficient means of High-throughput metabolic profiling and metadata analyses of the six species of the Fraxinus for comparative analysis.

During metabolomic analysis we specifically focused on the comparative analysis of the foliar chemistry between blue and Manchurian ashes, since these two species have different levels of resistance against EAB. Paired metabolomics analysis was conducted between blue and Manchurian ashes using the XCMS bioinformatics platform to delineate the diversity of putative defensive metabolites that may play a role in providing resistance against EAB. The cloud map (Figure 4) generated after paired comparison between blue and Manchurian ashes revealed the identification of 247 metabolite feature $(p<0.01)$. Metabolomic analysis further revealed the presence of compounds, with the majority of them belonging to phenolics, coumarins, lignans and secoiridoids, which are characteristic features of the genus Fraxinus. A total of 35 putative 
compounds were identified from blue and Manchurians ashes (Table 2), most of these compounds were upregulated in Manchurian ash. High-throughput metabolomic data analysis demonstrated the putative identification of secoiridoid compounds, ligstroside and oleuropin identified in significantly higher concentrations (37 and 58-fold) in Manchurian ash. Secoiridoids have biological activity against gram-positive and gram-negative bacteria, herbivores and have anti-inflammatory effects [33-35]. Similarly, eight secoiridoid glucosides were reported from the leaves of F. oxycarba [24], especially oleuropein, ligstroside, 10-hydroxyoleuropein and 10-hydroxyligstroside. Oleuropein and ligstroside have been documented from Fraxinus excelsior [12] and in foliage and phloem tissues of the F. americana, F. pennsylvanica, F. mandshurica and F. exciclor $[14,18,36]$. In addition, secoiridoids, oleuropein and ligstroside have been reported from the leaves of F. angustifolia (Vahl) [25].

In this study, paired untargeted metabolomics also helped identify lignans from blue and Manchurian ashes. Matairesinol, pinoresinol glucoside and 8-hydroxypinoresinol-4-glucoside were identified in significantly higher concentrations (7.0, 122 and 34-fold, respectively) in Manchurian ash in contrast to blue ash. Previous investigation reported the presence of three lignans, (+)-pinoresenol-4'-O- $\beta$-D-glucopyranoside, (+)-fraxiresinol-1-O- $\beta$-D-glucopyranoside and (+)-1-hydroxypinoresinol-4'-O- $\beta$-D-glucopyranoside from the leaves of F. oxycarba [24]. Pinoresinol, 8-hydroxypinoresinol, fraxiresinol, 8-hydroxysyringaresinol, pinoresinol-4-O- $\beta$-D-glucopyranoside and 8-hydroxypinoresinol-4-O- $\beta$-D-glucopyranoside have been reported from Fraxinus spp., including F. mandshurica and F. mandshurica var. japonica [12,17,37,38].

Higher constitutive expressions of an enzyme (phenylcoumaranbenzylic ether reductase) was identified from Manchurian ash that is involved in lignan biosynthesis. Furthermore, this study identified pinoresinol dihexoside unique to Manchurian ash and reported pinoresinol related compounds in higher amounts than green, white and black ashes [18]. Pinoresinol dihexoside and pinoresinol has been shown to have antifeeding and growth inhibiting properties against several insects [39-41]. Metabolomic analysis also showed the presence of an iridoid glycoside, verbenalin from blue and Manchurians ashes. Verbenalin was identified highly upregulated (64-fold) in Manchurian ash in comparison with blue ash. Similarly, an iridoid glucoside, 7-epi-7-O-(E)-caffeoylloganic acid have been identified from the dried leaves of Fraxinus griffithii [42]. Recently, putative iridoid glycosides were reported from the leaves of a European common ash, Fraxinus excelsior, which is well known for its anti-herbivory terpenoid derivatives [36]. Interestingly enough, Sambles and co-workers [36] reported reduced levels of the iridoid glycosides in tolerant ash, Fraxinus excelsior. Metabolomics also revealed the identification of the coumarin, fraxinol, in significant higher concentrations ( 9 fold) in Manchurian rather than blue ash. Coumarins have been well documented as the hallmark of blue and Manchurian ashes and as determinants of resistance against EAB. Metabolomic analysis revealed sesquiterpenoids (ar-artemisene, ar-turmerone and clovanediol diacetate), a diterpene (totarol) and a sesquiterpene lactone (parthenolide) from the blue and Manchurian ashes (Table 2), not documented in previous studies $[14,15,18,19]$.Apart from the reported metabolites upregulated in Manchurian ash, putative up-regulated compounds have also been identified from blue ash (e.g., dicyclomine, aphidicolin, parthenolide, famciclovir, ar-turmerone and myriocin) that are endemic to North America and have been colonized by EAB at lower levels than other North American ashes [7]. The distinct foliar profile of blue ash observed in this investigation may contribute to its constitutive resistance in comparison to other North American ashes. 


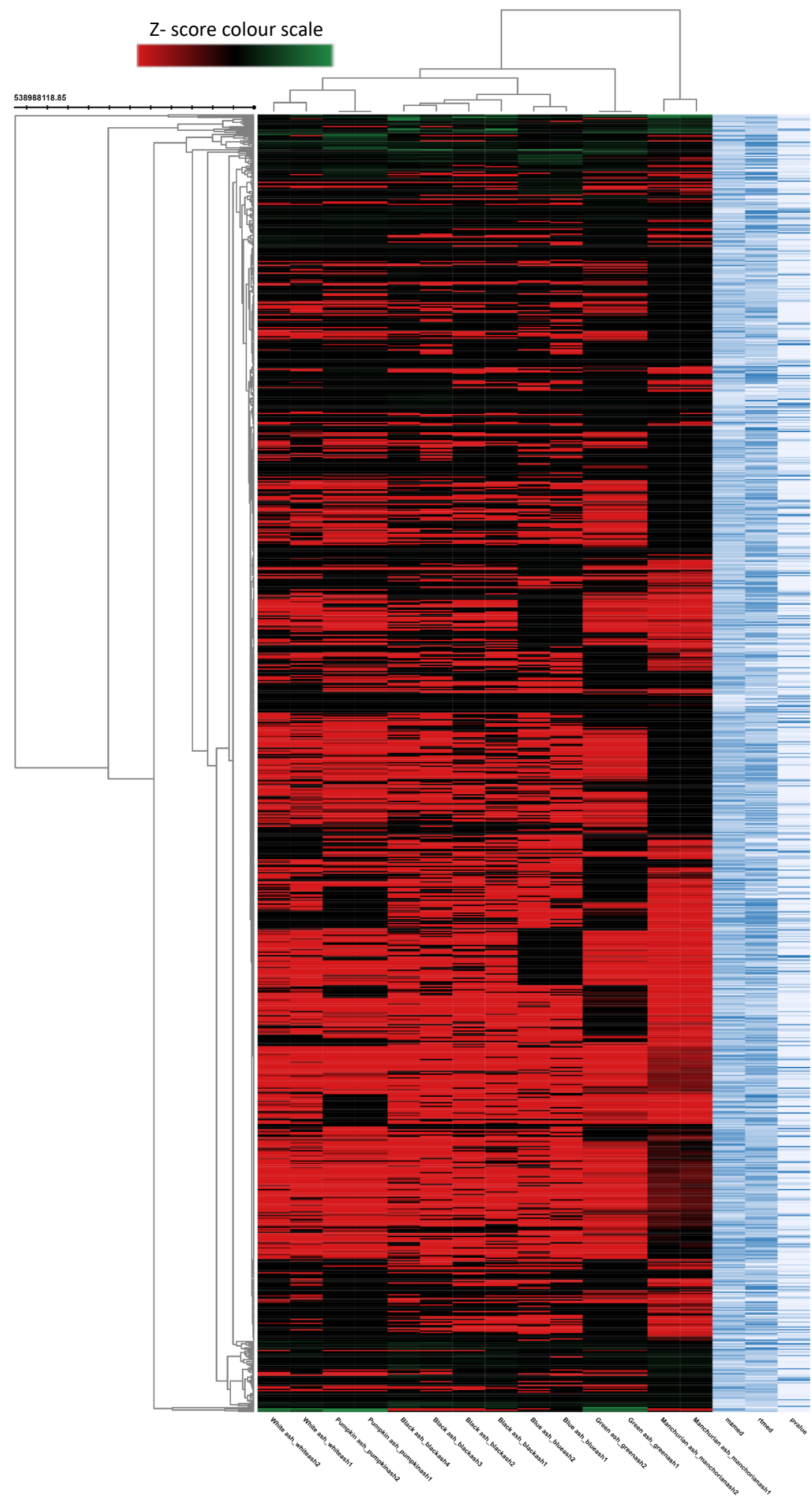

Figure 3. The heat map (dendrogram view) revealing the comparison of metabolite features between the different Fraxinus spp. (blue, Manchurian, black, green, pumpkin, and white ashes). In dendrogram, each row represents a metabolite feature and each column represents ash species. Metabolite features, the level of which varies significantly $(p<0.05)$ between different species are projected on the heat map and were used for sample clustering. The row $\mathrm{Z}$ score (scaled expression) value of each feature is plotted in red (high abundance) to green color (low abundance) scale. 


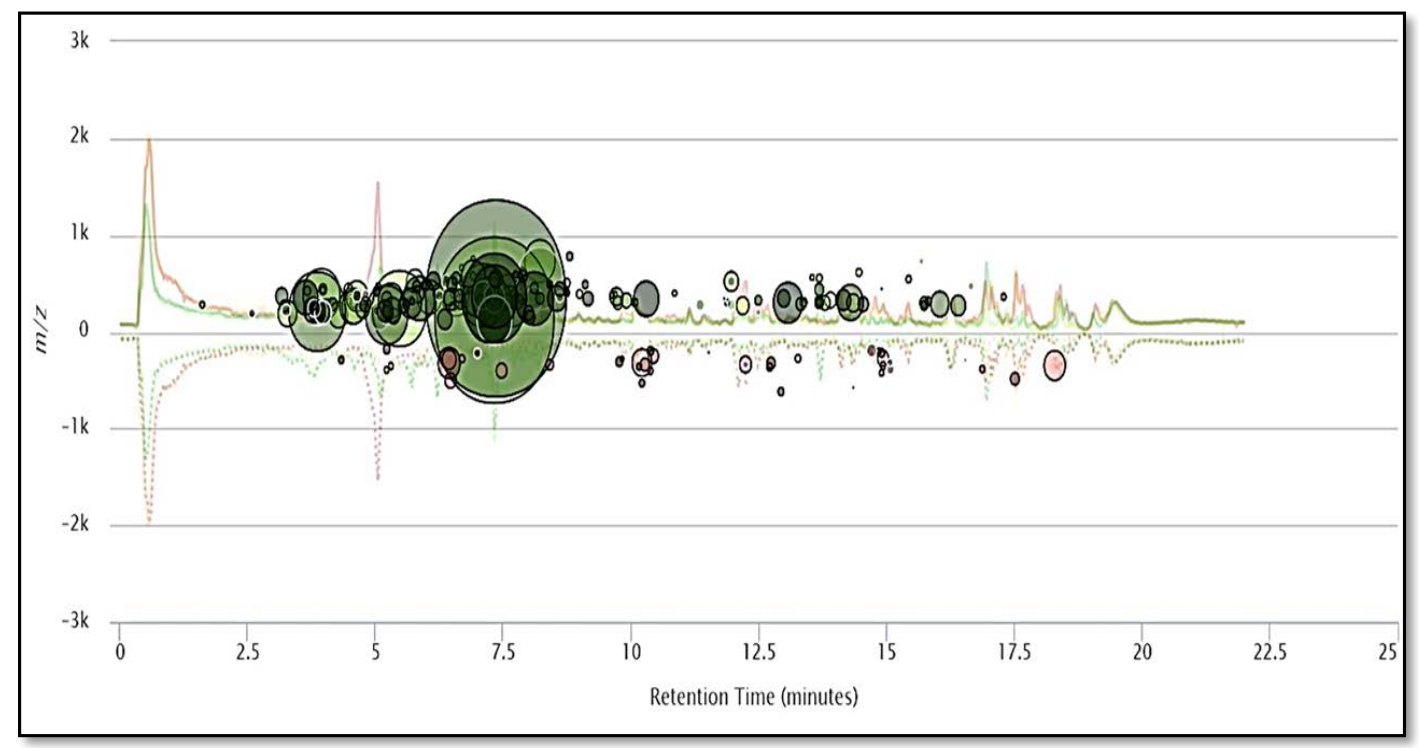

Figure 4. The metabolomic cloud map generated after paired untargeted metabolomics, showing the up- and- down regulated metabolites between blue and Manchurian ashes. The metabolic cloud map revealed a total of 247 metabolite features $(p<0.01)$ between blue and Manchurian ashes. The green circles represent upregulated metabolite features in Manchurian ash, whereas brown circles represent down regulated metabolite feature in blue ash. The cloud map was generated using XCMS bioinformatics platform for metabolomics. 
Table 2. Metabolomic analysis (paired untargeted metabolomics) revealing the putative identification of up- and- down regulated metabolites in Manchurian ash in comparison to Blue ash. Formula, $\mathrm{M}+\mathrm{H}$, RT, fold change, up- and- down regulation of metabolites, and $p$ value (Welch's $t$ test) among reported compounds.

\begin{tabular}{|c|c|c|c|c|c|c|c|c|}
\hline No & Compound Name & Formula & Actual Mass & $\mathbf{M}+\mathbf{H}$ & RT & Fold Change & Up/Down & $p$ Value \\
\hline 1 & Dicyclomine & $\mathrm{C}_{19} \mathrm{H}_{35} \mathrm{NO}_{2}$ & 309.487 & 310.2736 & 9.78 & 50 & DOWN & 0.00047 \\
\hline 2 & $N$-hydroxyamphetamine & $\mathrm{C}_{9} \mathrm{H}_{13} \mathrm{NO}$ & 151.205 & 152.1069 & 8.03 & 13 & UP & 0.00055 \\
\hline 3 & Norethynodrel & $\mathrm{C}_{20} \mathrm{H}_{26} \mathrm{O}_{2}$ & 298.419 & 299.2002 & 15.8 & 30 & UP & 0.00056 \\
\hline 4 & 4-(3,4-Difluorophenyl) piperidine & $\mathrm{C}_{11} \mathrm{H}_{13} \mathrm{~F}_{2} \mathrm{~N}$ & 197.101 & 198.1086 & 10.38 & 30 & DOWN & 0.00059 \\
\hline 5 & Erythronolide A & $\mathrm{C}_{17} \mathrm{H}_{30} \mathrm{~N}_{4}$ & 418.527 & 419.2685 & 8.7 & 18 & UP & 0.00067 \\
\hline 6 & Phenol, 4-amino-2,6-bis(1-piperidinylmethyl)- & $\mathrm{C}_{18} \mathrm{H}_{29} \mathrm{~N}_{3} \mathrm{O}$ & 303.450 & 304.2314 & 14.31 & 32 & $\mathrm{UP}$ & 0.00082 \\
\hline 7 & $\begin{array}{l}\text { Butyronitrile, 2,2-diphenyl-4-(4-(3-hydroxymethyl-2-oxo-1- } \\
\text { benzimidaizolinyl) piperidino)- }\end{array}$ & $\mathrm{C}_{29} \mathrm{H}_{30} \mathrm{~N}_{4} \mathrm{O}_{2}$ & 466.585 & 467.5260 & 9.1 & 28 & $\mathrm{UP}$ & 0.00094 \\
\hline 8 & Pinoresinol glucoside & $\mathrm{C}_{26} \mathrm{H}_{32} \mathrm{O}_{11}$ & 520.525 & 521.2012 & 6.39 & 122 & UP & 0.01517 \\
\hline 9 & 8-hydroxypinoresinol 4-glucoside & $\mathrm{C}_{26} \mathrm{H}_{32} \mathrm{O}_{12}$ & 536.530 & 537.1959 & 4.75 & 34 & UP & 0.01435 \\
\hline 11 & $N, N$-Dicyclohexyl-2,3,4,5,6-pentahydroxyhexanamide & $\mathrm{C}_{18} \mathrm{H}_{33} \mathrm{NO}_{6}$ & 359.463 & 360.2377 & 10.16 & 15 & DOWN & 0.00097 \\
\hline 12 & 2,2'-Disulfanediylbis[Nt-(hepta-1,6-dien-4-yl) aniline] & $\mathrm{C}_{26} \mathrm{H}_{32} \mathrm{~N}_{2} \mathrm{~S}_{2}$ & 436.200 & 437.2079 & 13.6 & 58 & UP & 0.00098 \\
\hline 13 & Matairesinol & $\mathrm{C}_{20} \mathrm{H}_{22} \mathrm{O}_{6}$ & 358.141 & 359.1482 & 7.9 & 6.7 & UP & 0.00550 \\
\hline 14 & $\begin{array}{l}\text { Benzamide, } N \text {-(2-(diethylamino) ethyl)-4-((1-oxopropyl) } \\
\text { amino)-, monohydrochloride }\end{array}$ & $\mathrm{C}_{16} \mathrm{H}_{26} \mathrm{ClN}_{3} \mathrm{O}_{2}$ & 327.171 & 328.2055 & 12.99 & 156 & UP & 0.00112 \\
\hline 15 & beta-Ionone & $\mathrm{C}_{13} \mathrm{H}_{20} \mathrm{O}$ & 192.151 & 193.1585 & 8.0 & 12 & UP & 0.00113 \\
\hline 16 & Ligstroside & $\mathrm{C}_{25} \mathrm{H}_{32} \mathrm{O}_{12}$ & 524.519 & 525.2226 & 7.34 & 37 & UP & 0.00118 \\
\hline 17 & 2-Methoxy-1-(phenylselanyl) decan-3-ol & $\begin{array}{l}\mathrm{C}_{17} \mathrm{H}_{28} \mathrm{O}_{2} \mathrm{Se} \\
\mathrm{C}_{17} \mathrm{H}_{28} \mathrm{O}_{2} \mathrm{Se}\end{array}$ & 344.125 & 345.1328 & 7.36 & 56 & UP & 0.00130 \\
\hline 18 & Totarol & $\mathrm{C}_{20} \mathrm{H}_{30} \mathrm{O}$ & 286.229 & 287.2366 & 16.04 & 264 & UP & 0.00144 \\
\hline 19 & Clovanediol diacetate & $\mathrm{C}_{19} \mathrm{H}_{30} \mathrm{O}_{4}$ & 322.214 & 323.2212 & 12.74 & 29 & DOWN & 0.00147 \\
\hline 21 & ar-Artemisene & $\mathrm{C}_{20} \mathrm{H}_{30}$ & 270.234 & 271.2416 & 16.41 & 109 & UP & 0.00171 \\
\hline 22 & 11,12-dihydroxy arachidic acid & $\mathrm{C}_{20} \mathrm{H}_{40} \mathrm{O}_{4}$ & 344.292 & 345.2994 & 8.22 & 20 & UP & 0.00174 \\
\hline 23 & 1-Docosylpyridin-1-ium bromide & $\mathrm{C}_{27} \mathrm{H}_{50} \mathrm{BrN}$ & 467.312 & 468.3465 & 17.52 & 57 & DOWN & 0.00221 \\
\hline 24 & Aphidicolin & $\mathrm{C}_{20} \mathrm{H}_{34} \mathrm{O}_{4}$ & 338.245 & 339.2525 & 10.29 & 35 & DOWN & 0.00236 \\
\hline 25 & Parthenolide & $\mathrm{C}_{15} \mathrm{H}_{20} \mathrm{O}_{3}$ & 248.141 & 249.1481 & 10.46 & 20 & DOWN & 0.00291 \\
\hline 26 & Pentaquine & $\mathrm{C}_{18} \mathrm{H}_{27} \mathrm{~N}_{3} \mathrm{O}$ & 301.215 & 302.2156 & 9.74 & 56 & UP & 0.00293 \\
\hline 27 & Famciclovir & $\mathrm{C}_{14} \mathrm{H}_{19} \mathrm{~N}_{5} \mathrm{O}_{4}$ & 321.143 & 322.1773 & 8.42 & 24 & DOWN & 0.00302 \\
\hline 28 & ar-Turmerone & $\mathrm{C}_{15} \mathrm{H}_{20} \mathrm{O}$ & 216.151 & 217.1583 & 14.92 & 22 & DOWN & 0.00309 \\
\hline 29 & Myriocin & $\mathrm{C}_{21} \mathrm{H}_{39} \mathrm{NO}_{6}$ & 401.277 & 402.2846 & 10.4 & 20 & DOWN & 0.00439 \\
\hline 30 & Coniferin & $\mathrm{C}_{16} \mathrm{H}_{22} \mathrm{O}_{8}$ & 342.131 & 343.1384 & 4.94 & 14 & UP & 0.07002 \\
\hline 31 & Isosyringinoside & $\mathrm{C}_{23} \mathrm{H}_{34} \mathrm{O}_{14}$ & 534.194 & 535.1834 & 6.36 & 54 & UP & 0.03068 \\
\hline 32 & Oleuropein & $\mathrm{C}_{25} \mathrm{H}_{32} \mathrm{O}_{13}$ & 540.184 & 541.2175 & 6.58 & 58 & UP & 0.00360 \\
\hline 33 & Hydroxytyrosol 1-O-glucoside & $\mathrm{C}_{14} \mathrm{H}_{20} \mathrm{O}_{8}$ & 316.115 & 317.1492 & 1.25 & 16 & UP & 0.03709 \\
\hline 34 & Verbenalin & $\mathrm{C}_{17} \mathrm{H}_{24} \mathrm{O}_{10}$ & 388.136 & 389.1437 & 3.11 & 64 & UP & 0.01169 \\
\hline 35 & Fraxinol & $\mathrm{C}_{11} \mathrm{H}_{10} \mathrm{O}_{5}$ & 222.052 & 223.0599 & 5.2 & 9.3 & UP & 0.00060 \\
\hline
\end{tabular}




\subsection{System Biology}

In order to expand further on the analysis and provide meaningful information about the metabolites identified from blue and Manchurian ashes, system biology analysis guided by XCMS metabolomics was also conducted. Some of the interesting dysregulated pathways identified between blue and Manchurian ashes can be observed in Figure 5. The top three dysregulated pathways identified in this study included, matairesinol biosynthesis $(p<0.0007)$, sinapate and ferulate biosynthesis $(p<0.0008)$, and GA12 biosynthesis $(p<0.0008)$ with an average overlap of metabolites, $89.0 \%, 71.4 \%$ and $71.0 \%$ between blue and Manchurian ashes, respectively. The data also suggest that even in dysregulated pathways with high average metabolite overlap (e.g., matairesoniol), the pathways that supply precursor metabolites (e.g., phenylpropanoid, $p<0.002$ ) have less metabolite overlap (57\%) between the blue and Manchurian ashes. These findings suggest that the dysregulated metabolic pathways operate differently in the blue and Manchurian ashes, and hence resulted in different regulation of metabolites between these two ashes.

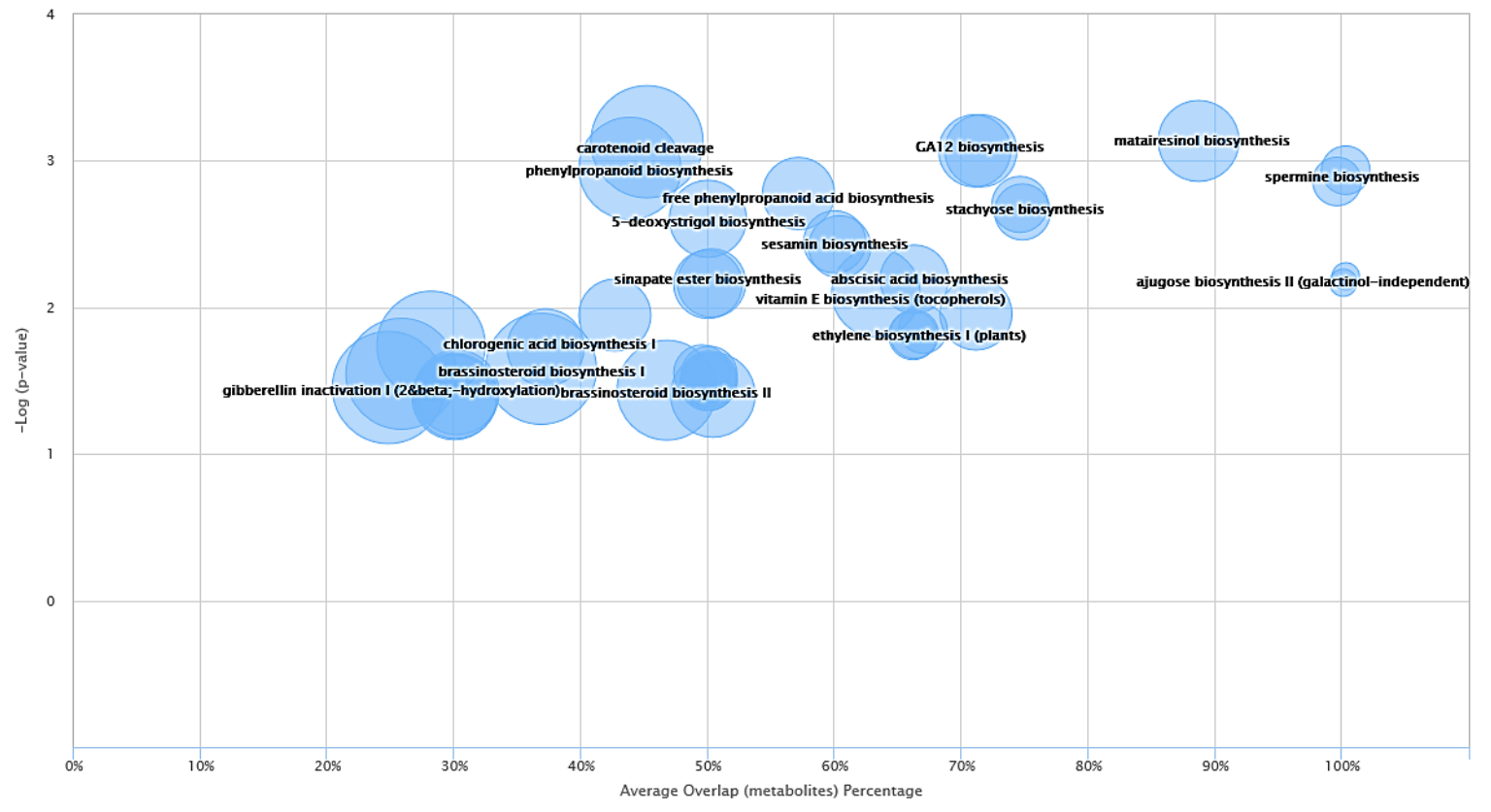

Figure 5. Metabolic cloud plot depicting the predictive pathway analysis between blue and Manchurian ashes. Each pathway is represented by a circle, the $\mathrm{x}$-axis in the cloud plot represents the percentage of metabolites overlap with in the pathway. The y-axis in the pathway represents the increased pathway significance. The radius of each circle is proportional to the total number of metabolites identified in that pathway. The cloud plot of dysregulated metabolites was generated $(p<0.05)$ using XCMS bioinformatics platform.

\subsection{Principal Component Analysis (PCA)}

To show the relationship among the six Fraxinus spp. under investigation, we used principal component analysis (PCA) that is considered one of the most widely used multivariate analysis tools in untargeted metabolic profiling and/or fingerprinting [43]. The PCA revealed the relationship between different species, which makes use of covariance or correlations among variables or metabolite features. Four main clusters were observed on the PCA plot (Figure 6), implying the influence of metabolite features in the clustering. The corresponding loading plot indicating the correlations between metabolites and their relationship to the sample grouping can be appreciated from Figure 6. We observed blue ash in a separate cluster (Dipetalae), implying its distinct chemistry and phylogeny (Figure 6). The green, white and pumpkin ashes clustered in a separate group (Melioides). Interestingly, we identified two separate clusters of section Fraxinus (referred as Fraxinus a and b), 
each occupied by black and Manchurian ashes. These data imply that metabolite features have more influence in the clustering of these two species, rather than their phylogenetic relationship. In contrast, high convergence in the phenolic profiles between black, Manchurian and European ashes has been observed in a study that placed them in the same taxonomic section [18]. It is important to mention that the PCA plot presented in the current study is based on 1000 metabolite features $(p<0.00001)$. Furthermore, the clonally propagated cultivar studied earlier [18], may not represent the open pollinated species of the genus Fraxinus in its true sense.
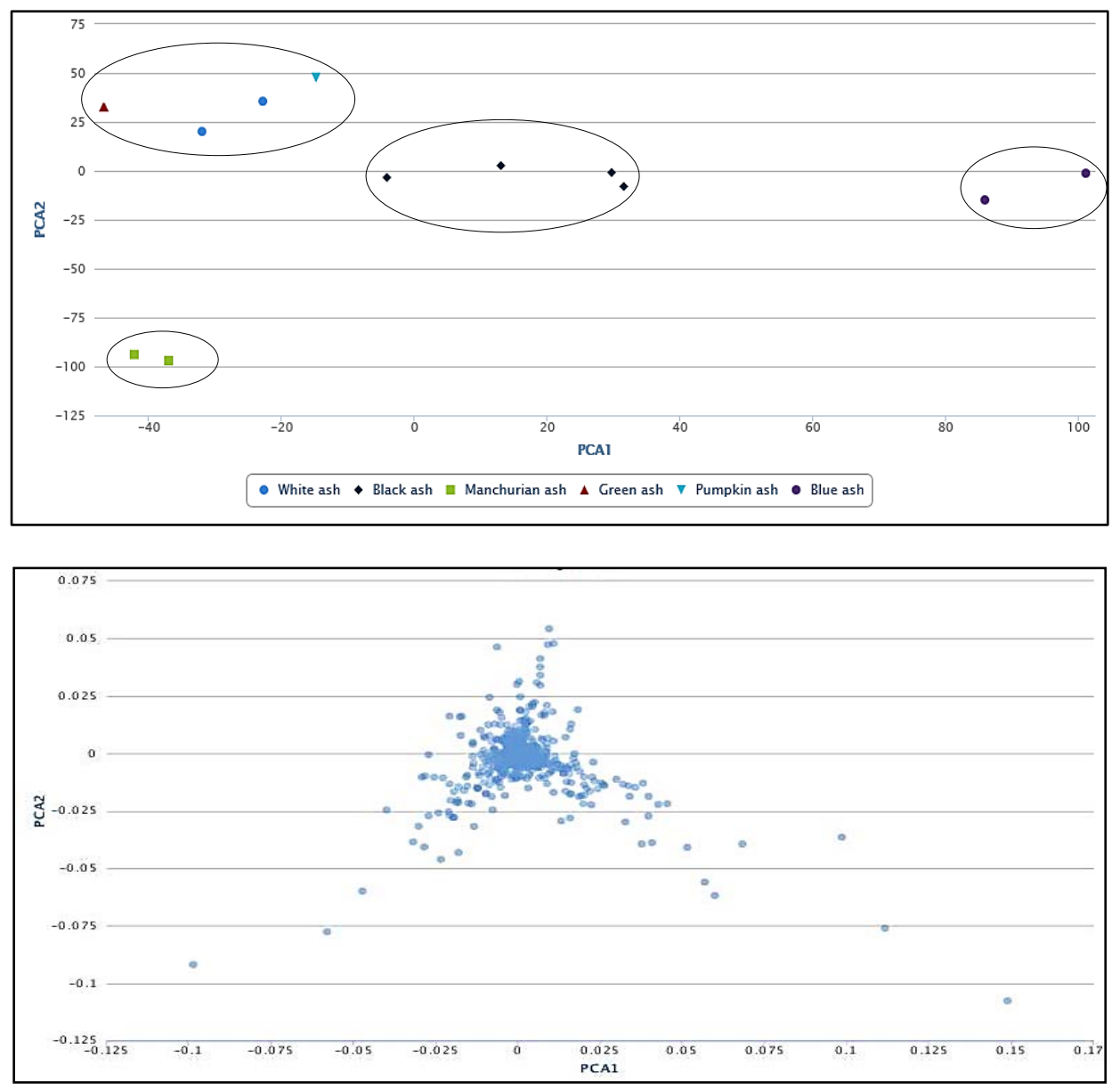

Figure 6. Principal component analysis (PCA; top panel), indicating the correlations between white, black, Manchurian, green, pumpkin and blue ashes. Loading plot (bottom panel) implying the relationship between the metabolite features that relate to the sample grouping. PCA and loading plots were generated using XCMS bioinformatics platform for metabolomics. Four clusters were observed on the PCA plot. Green, white and pumpkin ashes were clustered in section, Meliodes. Two clusters were observed for the section Fraxinus (referred as Fraxinus a and b), occupied by black and Manchurian ashes. Blue ash was clustered in a section, Dipetelae.

\section{Methods and Materials}

\subsection{Plants}

Fraxinus pennsylvanica var. subintegerrima (Vahl) Fern. (Green ash), F. americana L. (White ash), F. profunda (Bush) Bush. (Pumpkin ash), F. quadrangulata Michx. (Blue ash) and F. nigra Marsh. (Black ash) leaves were collected in June, July and August 2004-2006 from Sault Ste. Marie (lat. $46^{\circ} 30^{\prime} \mathrm{N}$, long. $84^{\circ} 20^{\prime} \mathrm{W}$ ), Sombra, (lat. $42^{\circ} 42^{\prime} \mathrm{N}$, long. $82^{\circ} 29^{\prime} \mathrm{W}$ ), Rondeau Provincial Park (lat. $42^{\circ} 17^{\prime} \mathrm{N}$, long. $81^{\circ} 52^{\prime} \mathrm{W}$ ), Chatham (lat. $42^{\circ} 24^{\prime} \mathrm{N}$, long. $82^{\circ} 11^{\prime} \mathrm{W}$ ), Cambridge (lat. $43^{\circ} 23^{\prime} \mathrm{N}$, long. $80^{\circ} 19^{\prime} \mathrm{W}$ ) and Windsor (lat. $42^{\circ} 18^{\prime} \mathrm{N}$, long. $83^{\circ} 01^{\prime} \mathrm{W}$ ), Ontario, Canada. Plants of F. mandshurica 
(Manchurian ash) were locally grown in Sault Ste. Marie and the leaves collected for extraction. Pressed voucher specimens of all species are deposited in the Natural Products Laboratory, Canadian Forest Service-Sault Ste. Marie herbarium.

\subsection{Extractions}

Bulk extract. Fresh or previously frozen leaf material was extracted at room temperature in two sequential steps: First, by steeping for $72 \mathrm{~h}$ in $70 \% \mathrm{EtOH}$ (aqueous), followed by maceration of the foliage, decanting and filtering of the extract; secondly, by steeping the remaining residue for an additional $24 \mathrm{~h}$ employing the same solvent system; however, using $30-50 \%$ of the initial volume. The combined and filtered aqueous ethanolic extracts were evaporated under reduced pressure, frozen and subjected to freeze drying to obtain freeze-dried extracts.

Green Ash, MacAlpine Site, Chatham, ON, 2.18 kg/24 L 70\% EtOH, 118.01 g; White Ash, Bellevue Park/GLFC, Sault Ste. Marie, ON, 3.45 kg/36 L 70\% EtOH, 393.38 g; Pumpkin Ash, Kopegaron Woods Conservation Area, Leamington, ON, 0.74 kg/20 L 70\% EtOH, 59.9 g; Blue Ash, D'Arcy McKeough Conservation Area, Sombra, ON, 5.62 kg/36 L 70\% EtOH, 233.50 g; Black Ash, Fish Hatchery Rd. Sault Ste. Marie, ON, 4.76 kg/38 L 70\% EtOH, $377.22 \mathrm{~g}$ and Manchurian Ash, GLFC Grounds, Sault Ste. Marie, $\mathrm{ON}, 0.04 \mathrm{~kg} / 3 \mathrm{~L} 70 \% \mathrm{EtOH} ; 5.9 \mathrm{~g}$.

\subsection{Fractionation}

Individual samples of green and blue ash freeze-dried extracts (100 g) were each mixed with $200 \mathrm{~g}$ of polyvinylpolypyrrolidone (PVPP) powder (Sigma). The homogeneous mixture of either sample was then placed on top of a PVPP packed $4 \mathrm{~L}$ Buchner funnel. Elution of individual extracts was carried out at a slow rate initially with $5 \mathrm{~L}$ of water followed by $5 \mathrm{~L}$ aliquots of increasing concentrations $(20 \%, 50 \%$, $70 \%$ and $100 \%$ ) of aqueous ethanol to produce five fractions. Each fraction was concentrated under vacuum and chromatographed one dimensionally on Whatman No.1 chromatography paper using one or more solvent systems: BAW (n-butanol-acetic acid-water, 4:1:5, upper phase), water, or acetic acid-water (15:85). Bands detected by absorbance/fluorescence under short wave light (254 nm) and long wave light $(366 \mathrm{~nm}$ ) were identified, cut and eluted with methanol. The samples were evaporated to dryness, dissolved in a minimum volume of methanol, and placed onto a PVPP column from which they were eluted sequentially with the following solvent systems: (i) $\mathrm{CH}_{2} \mathrm{Cl}_{2}$-EtOH-MeCOEt-Me $2 \mathrm{CO}$ (1:1:1:1), (ii) EtOH-MeCOEt-Me ${ }_{2} \mathrm{CO}-\mathrm{H}_{2} \mathrm{O}$ (1:1:1:1) and (iii) EtOH- $\mathrm{H}_{2} \mathrm{O}$ (1:1). Final clean up and purification of the compounds was achieved on a Sephadex LH-20 column $(1 \mathrm{~cm} \times 50 \mathrm{~cm})$, using methanol as the eluting solvent.

\subsection{Identification of Isolated Compounds}

UV spectra were recorded on a UV-Vis Beckman DU series 800 spectrophotometer (Brea, California, CA, USA). ${ }^{1} \mathrm{H}-\mathrm{NMR}$ and ${ }^{13} \mathrm{C}-\mathrm{NMR}$ spectra were recorded on a Bruker AMX-400 spectrometer (Billerica, MA, USA), at $500 \mathrm{MHz}$ and $125 \mathrm{MHz}$ respectively; samples were dissolved in DMSO- $d_{6}$ with TMS as an internal standard. Structures of purified compounds were determined according to standard methods [44,45] acid hydrolysis in $2 \mathrm{M}$ and $0.1 \mathrm{M} \mathrm{HCl}$ (mild hydrolysis) at $100{ }^{\circ} \mathrm{C}$ for $60 \mathrm{~min}$; enzymatic hydrolysis with $\beta$-glucosidase (Sigma-Aldrich, St. Louis, MO, USA) using an acetate buffer ( $\mathrm{pH}$ ); hydrogen peroxide oxidation; UV spectroscopy; ${ }^{1} \mathrm{H}-\mathrm{NMR} ;{ }^{13} \mathrm{C}-\mathrm{NMR}$ and FAB-mass spectroscopy (positive and negative), and by comparison with authentic samples where available. The glycosides and aglycones obtained by hydrolysis of isolated compounds were identified by co-chromatography with authentic samples (Sigma-Aldrich, St. Louis, MO, USA; Apin Chemicals LTD., Abingdon, OX., United Kingdom and Extrasynthese, Genay Cedex, France) using PC, TLC, HPLC and UPLC. Sugars released by hydrolysis were identified by PC and TLC using available standards. 


\subsection{Preparation of Extracts for HPLC-MS/MS}

The crude freeze-dried extracts were dissolved in Acetonitrile (AcN) (LC/MS grade, Fisher Scientific, Ottawa, ON, Canada) at concentrations of $10 \mathrm{mg} / \mathrm{mL}$ and were filtered through $0.22 \mu \mathrm{m}$ GHP filters (Acrodisc Syringe Filters, Pall Corporation, Quebec, QC, Canada) prior to HPLC-MS/MS analysis.

\subsection{HPLC-MS/MS (ORBITRAP)}

High performance liquid chromatography was performed using a Thermo Scientific LTQ Orbitrap Discovery (MS 2.5.5) equipped with an Autosampler Accela AS 2.2.1, and pump 1.04.05. The instrument was equipped with a Syncronis C18, Thermo Scientific column: $50 \mathrm{~mm}$ length, $2.1 \mathrm{~mm}$ I.D., and $1.7 \mu \mathrm{m}$ particle size that was operating at normal room temperature. Injection volumes were $10 \mu \mathrm{L}$. A gradient technique was employed in this study with a flow rate of $0.2 \mathrm{~mL} / \mathrm{min}$. Solvent A was composed of acetonitrile $(\mathrm{AcN})$ acidified with $0.1 \mathrm{vol} \%$ of formic acid whereas solvent B was composed of water acidified with $0.1 \mathrm{vol} \%$ of formic acid. The gradient was programmed as follows: Solvent A: 2 vol \%, increased to $10 \mathrm{vol} \%$ at $2 \mathrm{~min}$, increased to $25 \mathrm{vol} \%$ at $6 \mathrm{~min}$, increased to $50 \mathrm{vol} \%$ at $10 \mathrm{~min}$, increased to $75 \mathrm{vol} \%$ at $14 \mathrm{~min}$, increased to $95 \mathrm{vol} \%$ at $18 \mathrm{~min}$, decreased to $2 \mathrm{vol} \%$ at $20 \mathrm{~min}$, followed by 2 min of isocratic elution with $2 \%$ of solvent A (total elution time $22 \mathrm{~min}$ ). The LTQ Orbitrap MS was equipped with an ESI source operating in the positive ionization mode using the following operating parameters: Electrospray voltage of $3.1 \mathrm{kV}$, sheath gas flow rate of 8 abu (arbitrary units), auxiliary gas flow rate of $1 \mathrm{abu}$, capillary temperature of $270{ }^{\circ} \mathrm{C}$, capillary voltage set to $49.00 \mathrm{~V}$, tube lens offset at $-148.43 \mathrm{~V}$. Instrument calibration was performed externally prior to running each sequence, employing the "Thermo Scientific Pierce LTQ Velos ESI positive ion calibration solutions." Accurate mass spectra of $[\mathrm{M}+\mathrm{H}]^{+}$ions were recorded from 100 to $1000 \mathrm{~m} / \mathrm{z}$, the mass resolution power of the mass analyzer was set to $30,000(\mathrm{~m} / \Delta \mathrm{m})$ at $m / z 400$. Nitrogen gas (purity $99.95 \%$ ) was used both as sheath gas and auxiliary gas and also served as the co collision gas in the HCD cell and the bath gas in the C-trap. Percentage peak areas of the compounds were calculated using Xcalibur (version 2.2, Thermo Scientific, Waltham, MA, USA) using the peak detection algorithm, ICIS, specifically designed for MS data that has superior peak detection efficiency at low MS signal levels.

\subsection{Untargeted Metabolomic Analysis}

Data were analyzed using multi-group method of XCMS online (https: / xcmsonline.scripps.edu) bioinformatics platform [46]. In addition, paired comparison between blue and Manchurians ashes was performed to identify putative up- and- down regulated metabolites. The HPLC-MS/MS raw data files from ORBITRAP (Discovery) were converted to mzXML format using Proteowizard, and were subsequently processed for peak detection, retention time correction, chromatogram alignment, metabolite feature metadata/statistical analysis, and putative identification using METLIN database. The parameter settings for XCMS processing were as follows: centWave for feature detection $(\Delta \mathrm{m} / \mathrm{z}=15 \mathrm{ppm}$, minimum peak width $=10 \mathrm{~s}$ and maximum peak width $=120 \mathrm{~s})$; obiwarp settings for retention-time correction (prof Step $=1$ ); and parameters for chromatogram alignment, including mzwid $=0.015$, minfrac $=0.5$ and $\mathrm{bw}=5$. The relative quantification of metabolite features was based on peak areas $[47,48]$.

\section{Conclusions}

The current study presents the first report on the High-throughput metabolomic analysis of the foliar chemistry of the six Fraxinus spp. Phenolics and flavonoids variations from the six Fraxinus spp. was identified, not documented in earlier studies. Compounds were purified, and the identities of phenolics and flavonoids were confirmed by NMR. Metabolomic profiling using HPLC-MS/MS in combination with NMR provided chemical differentiation of the six Fraxinus spp., hence, an insight on the foliar phytochemical diversity of these plants. Metabolomics provided a useful tool for the 
rapid identification of metabolites and revealed coumarins, secoiridoids and lignans from blue and Manchurian ashes.

The striking feature of this study, the paired untargeted metabolomic analysis revealed several putative defensive compounds for the first time from blue and Manchurian ashes (Table 2). Interestingly, we identified sesquiterpenoids, a diterpene and a sesquiterpene lactone, not documented earlier from these ashes. The systems biology analysis unique to this investigation suggests the differential regulation of metabolites between blue and Manchurian ashes. Further, paired metabolomics showed majority of the compounds upregulated in Manchurian ash, which may suggest their role in providing resistance, and reflects its co-evolutionary history with A. planipennis where they coexist in their native habitat. These data suggest that clear differences exist in the chemical defensive profiles between resistant ash species and its susceptible counterparts in North America. Our study supports the potential role of coumarins, secoiridoids, lignans, sesquiterpenoids, diterpenes and sesquiterpene lactones in providing constitutive resistance to Manchurian ash, hence the synergistic action of the upregulated defensive compounds may provide a mechanism of resistance to Manchurian ash against $\mathrm{EAB}$.

The autonomous untargeted metabolomics provided High-throughput screening and metabolic profiling of phytochemicals from six Fraxinus spp. that can provide the groundwork for the future studies. Since, a significant portion $(25 \%)$ of the ash genome encodes unique or orphan genes [30], metabolomics (especially the systems biology approach) would prove to be a useful tool in order to facilitate the putative identification of metabolites and key metabolic pathways that can help understand and identify gene functions. The metabolomics would prove to be especially useful in the discovery of potential biomarkers for the rapid and early screening of diseased ash trees and resistant ash varieties for the breeding programs.

Author Contributions: Conceptualization, S.S.Q. and M.M.A.-Z.; Data curation, S.S.Q. and M.M.A.-Z.; Formal analysis, S.S.Q. and M.M.A.-Z.; Funding acquisition, M.M.A.-Z.; Investigation, S.S.Q., D.A.L. and M.M.A.-Z.; Methodology, S.S.Q., D.A.L. and M.M.A.-Z.; Project administration, M.M.A.-Z.; Resources, M.M.A.-Z.; Bioinformatics software, S.S.Q. and M.M.A.-Z.; Supervision, M.M.A.-Z.; Validation, S.S.Q., D.A.L. and M.M.A.-Z.; Writing-original draft, S.S.Q. and M.M.A.-Z.; Writing—review and editing, S.S.Q., D.A.L. and M.M.A.-Z.

Funding: The project was carried out with financial support from Great Lakes Forestry Centre, Canadian Forest Service, Natural Resources Canada.

Conflicts of Interest: The authors declare no conflict of interest.

\section{References}

1. Poland, T.M.; McCullough, D.G. Emerald ash borer: Invasion of the urban forest and the threat to North America's ash resource. J. For. 2006, 104, 118-124.

2. Siegert, N.W.; McCullough, D.G.; Liebhold, A.M.; Telewski, F.D. Dendrochronological reconstruction of the epicentre and early spread of Emerald Ash Borer in North America. Divers. Distrib. 2014, 20, 847-858. [CrossRef]

3. Farrar, J.L. Trees in Canada; Natural Resources Canada, Canadian Forest Service: Ottawa, ON, Canada; Fitzhenry and Whiteside Limited: Markham, ON, Canada, 1995.

4. Cappaert, D.; McCullough, D.G.; Poland, T.M.; Siegert, N.W. Emerald ash borer in North America: A research and regulatory challenge. Am. Entomol. 2005, 51, 152-165. [CrossRef]

5. Rebek, E.J.; Herms, D.A.; Smitley, D.R. Interspecific variation in resistance to Emerald Ash Borer (Coleoptera: Buprestidae) among North American and Asian ash (Fraxinus spp.). Environ. Entomol. 2008, 37, 242-246. [CrossRef]

6. Klooster, W.S.; Herms, D.A.; Knight, K.S.; Herms, C.P.; McCullough, D.G.; Smith, A.; Gandhi, K.J.K.; Cardina, J. Ash (Fraxinus spp.) mortality, regeneration, and seed bank dynamics in mixed hardwood forests following invasion by Emerald Ash Borer (Agrilus planipennis). Biol. Invasions 2014, 16, 859-873. [CrossRef]

7. Anulewicz, A.C.; Mccullough, D.G.; Cappaert, D.L.; Poland, T.M. Host range of the Emerald Ash Borer (Agrilus planipennis Fairmaire) (Coleoptera: Buprestidae) in North America: Results of multiple-choice field experiments. Environ. Entomol. 2008, 37, 230-241. [CrossRef] 
8. Tanis, S.R.; McCullough, D.G. Differential persistence of blue ash and white ash following Emerald Ash Borer invasion. Can. J. For. Res. 2012, 42, 1542-1550. [CrossRef]

9. Westwood, M.; Oldfield, S.; Jerome, D.; Romero-Severson, J. Fraxinus Quadrangulate. The IUCN Red List of Threatened Species, 2017: E. Available online: https:/ /www.iucnredlist.org/species/61919112/61919114 (accessed on 24 April 2018).

10. Kovacs, K.F.; Haight, R.G.; McCullough, D.G.; Mercader, R.J.; Siegert, N.W.; Liebhold, A.M. Cost of potential Emerald Ash Borer damage in U.S. communities, 2009-2019. Ecol. Econom. 2010, 69, 569-578. [CrossRef]

11. Kovacs, K.F.; Mercader, R.J.; Haight, R.G.; Siegert, N.W.; McCullough, D.G.; Liebhold, A.M. The influence of satellite populations of Emerald Ash Borer on projected economic costs in U.S. communities, 2010-2020. J. Environ. Manag. 2011, 92, 2170-2181. [CrossRef] [PubMed]

12. Kostova, I.; Iossifova, T. Chemical components of Fraxinus species. Fitoterapia 2007, 78, 85-106. [CrossRef] [PubMed]

13. Dunn, J.P.; Potter, D.A.; Kimmerer, T.W. Carbohydrate reserves, radial growth, and mechanisms of resistance of oak trees to phloem-boring insects. Oecologia 1990, 83, 458-468. [CrossRef] [PubMed]

14. Eyles, A.; Jones, W.; Riedl, K.; Cipollini, D.; Schwartz, S.; Chan, K.; Herms, D.A.; Bonello, P. Comparative phloem chemistry of Manchurian (Fraxinus mandshurica) and two North American ash species (Fraxinus americana and Fraxinus pennsylvanica). J. Chem. Ecol. 2007, 33, 1430-1448. [CrossRef] [PubMed]

15. Cipollini, D.; Wang, Q.; Whitehill, J.G.A.; Powell, J.R.; Bonello, P.; Herms, D.A. Distinguishing defensive characteristics in the phloem of ash species resistant and susceptible to Emerald Ash Borer. J. Chem. Ecol. 2011, 37, 450-459. [CrossRef] [PubMed]

16. Greger, H.; Hofer, O. New unsymmetrically substituted tetrahydrofurofuran lignans from Artemisia absinthiumAssignment of the relative stereochemistry by lanthanide chemical shifts. Tetrahedron 1980, 36, 3551-3558. [CrossRef]

17. Tsukamoto, H.; Hisada, S.; Nishide, S. Lignans from bark of Fraxinus mandshurica var. japonica and F. japonica. Chem. Pharm. Bull. 1984, 32, 4482-4489. [CrossRef]

18. Whitehill, J.G.A.; Opiyo, S.O.; Koch, J.L.; Herms, D.A.; Cipollini, D.F.; Bonello, P. Interspecific comparison of constitutive ash phloem phenolic chemistry reveals compounds unique to Manchurian ash, a species resistant to Emerald Ash borer. J. Chem. Ecol. 2012, 38, 499-511. [CrossRef] [PubMed]

19. Chakraborty, S.; Whitehill, J.G.A.; Hill, A.L.; Opiyo, S.O.; Cipollini, D.; Herms, D.A.; Bonello, P. Effects of water availability on Emerald Ash Borer larval performance and phloem phenolics of Manchurian and black ash. Plant Cell Environ. 2014, 37, 1009-1021. [CrossRef] [PubMed]

20. Adfa, M.; Yoshimura, T.; Komura, K.; Koketsu, M. Antitermite activities of coumarin derivatives and scopoletin from Protium javanicum Burm. f. J. Chem. Ecol. 2010, 36, 720-726. [CrossRef] [PubMed]

21. Harborne, J.B. Recent advances in chemical ecology. Nat. Prod. Rep. 1999, 16, 509-523. [CrossRef] [PubMed]

22. Kowalczyk, B.; Olechnowicz-Stepien, W. Study of Fraxinus excelsior L. leaves. I. Phenolic acids and flavonoids. Herba Pol. 1988, 34, 7-13.

23. Grujic-Vaciæ, J.; Ramic, S.; Bašiæ, F.; Bosnic, T. Phenolic compounds in the bark and leaves of Fraxinus I sorts. Acta Biol. Med. Exp. 1989, 14, 17-30.

24. Hosny, M. Secoiridoid glucosides from Fraxinus oxycarba. Phytochemistry 1998, 47, 1569-1576. [CrossRef]

25. Ayouni, K.; Berboucha-Rahmani, M.; Kim, H.K.; Atmani, D.; Verpoorte, R.; Choi, Y.H. Metabolomic tool to identify antioxidant compounds of Fraxinus angustifolia leaf and stem bark extracts. Ind. Crops Prod. 2016, 88, 65-77. [CrossRef]

26. Takenaka, Y.; Tanahashi, T.; Shintaku, M.; Sakai, T.; Nagakura, N. Secoiridoid glucosides from Fraxinus americana. Phytochemistry 2000, 55, 275-284. [CrossRef]

27. Cleary, M.R.; Andersson, P.F.; Broberg, A.; Elfstrand, M.; Daniel, G.; Stenlid, J. Genotypes of Fraxinus excelsior with different susceptibility to the ash dieback pathogen Hymenoscyphus pseudoalbidus and their response to the phytotoxin viridiol-A metabolomic and microscopic study. Phytochemistry 2014, 102, 115-125. [CrossRef] [PubMed]

28. Schultz, J.C. Tannin-insect interactions. In Chemistry and Significance of condensed tannins, 3rd ed.; Hemingway, R.W., Karchesy, J.J., Branham, S.J., Eds.; Springer: New York, NY, USA, 1989; pp. 417-433.

29. Abou-Zaid, M.M.; Helson, B.; Nozzolillo, C.; Arnason, J.T. Gallates from red maple, Acer rubrum as a source of resistance to forest tent caterpillar, Malacosoma disstria. J. Chem. Ecol. 2001, 27, 2517-2527. [CrossRef] [PubMed] 
30. Sollars, E.S.; Harper, A.L.; Kelly, L.J.; Sambles, C.M.; Ramirez-Gonzalez, R.H.; Swarbreck, D.; Kaithakottil, G.; Cooper, E.D.; Uauy, C.; Havlickova, L.; et al. Genome sequence and genetic diversity of European ash trees. Nature 2007, 541, 212-216. [CrossRef] [PubMed]

31. Sambles, C.M.; Salmon, D.L.; Florance, H.; Howard, T.P.; Smirnoff, N.; Nielsen, L.R.; McKinney, L.V.; Kjær, E.D.; Buggs, R.J.A.; Studholme, D.J.; et al. Ash leaf metabolomes reveal differences between trees tolerant and susceptible to ash dieback disease. Sci. Data 2017, 4, 170190. [CrossRef] [PubMed]

32. Deu-Pons, J.; Schroeder, M.P.; Lopez-Bigas, N.J. Heatmap: An interactive heatmap viewer for the web. Bioinformatics 2014, 30, 1757-1758. [CrossRef] [PubMed]

33. Konno, K.; Hirayama, C.; Yasui, H.; Nakamura, M. Enzymatic activation of oleuropein: A protein crosslinker used as a chemical defense in the privet tree. Proc. Natl. Acad. Sci. USA 1999, 96, 9159-9164. [CrossRef] [PubMed]

34. Kumarasamy, Y.; Nahar, L.; Cox, P.J.; Jaspars, M.; Sarker, S.D. Bioactivity of secoiridoid glycosides from Centaurium erythraea. Phytomedicine 2003, 10, 344-347. [CrossRef] [PubMed]

35. Dinda, B.; Debnath, S.; Harigaya, Y. Naturally occurring secoiridoids and bioactivity of naturally occurring iridoids and secoiridoids. A review, part 2. Chem. Pharm. Bull. 2007, 55, 689-728. [CrossRef] [PubMed]

36. Chen, Y.; Whitehill, J.G.A.; Bonello, P.; Poland, T.M. Differential response in foliar chemistry of three ash species to Emerald Ash Borer adult feeding. J. Chem. Ecol. 2011, 37, 29-39. [CrossRef] [PubMed]

37. Terazawa, M.; Sasaya, T. Extractives of Yachidamo Fraxinus mandshurica RUPR. var. japonica MAXIM. III. Extractives of woods. Phenolic compounds in sapwood. Mokuzai Gakkaishi 1971, 17, 167-173.

38. Baxter, H.; Harborne, J.B.; Moss, G.P. Phytochemical Dictionary. In A Handbook of Bioactive Compounds from Plants, 2nd ed.; Taylor and Francis LTD: London, UK, 1999.

39. Miyazawa, M.; Ishikawa, Y.; Kasahara, H.; Yamanaka, J.I.; Kameoka, H. An insect growth inhibitory lignan from flower buds of Magnolia fargesii. Phytochemistry 1994, 35, 611-613. [CrossRef]

40. Cabral, M.M.O.; Kelecom, A.; Garcia, E.S. Effects of the lignan pinoresinol on the moulting cycle of the bloodsucking bug Rhodnius prolixus and of the milkweed bug Oncopeltus fasciatus. Fitoterapia 1999, 70, 561-567. [CrossRef]

41. Garcia, E.S.; Cabral, M.M.; Schaub, G.A.; Gottlieb, O.R.; Azambuja, P. Effects of lignoids on a hematophagous bug, Rhodnius prolixus: Feeding, ecdysis and diuresis. Phytochemistry 2000, 55, 611-616. [CrossRef]

42. Macahig, R.A.; Harinantenaina, L.; Matsunami, K.; Otsuka, H.; Takeda, Y.; Shinzato, T. Secoiridoid and iridoid glucosides from the leaves of Fraxinus griffithii. J. Nat. Med. 2010, 64, 1-8. [CrossRef] [PubMed]

43. Gowda, H.; Ivanisevic, J.; Johnson, C.H.; Kurczy, M.E.; Benton, H.P.; Rinehart, D.; Nguyen, T.; Ray, J.; Kuehl, J.; Arevalo, B.; et al. Interactive XCMS Online: Simplifying advanced metabolomic data processing and subsequent statistical analyses. Anal. Chem. 2014, 86, 6931-6939. [CrossRef] [PubMed]

44. Dey, P.M.; Harborne, B. Plethora of polyphenols Plant Phenolics. In Methods in Plant Biochemistry; Harborne, B., Ed.; Academic Press: London, UK, 1989; Volume 1.

45. Fossen, T.; Andersen, O.M. Spectroscopic techniques applied to flavonoids. In Flavonoids: Chemistry, Biochemistry and Applications; Andersen, O.M., Markham, K.R., Eds.; CRC Press: Boca Raton, FL, USA, 2006; pp. 37-142.

46. Benton, H.P.; Ivanisevic, J.; Mahieu, N.G.; Kurczy, M.E.; Johnson, C.H.; Franco, L.; Rinehart, D.; Valentine, E.; Gowda, H.; Ubhi, B.K.; et al. Autonomous metabolomics for rapid metabolite identification in global profiling. Anal. Chem. 2015, 87, 884-891. [CrossRef] [PubMed]

47. Ivanisevic, J.; Benton, P.H.; Rinehart, D.; Epstein, A.; Kurczy, M.E.; Boska, M.D.; Gendelman, H.E.; Siuzdak, G. An interactive cluster heat map to visualize and explore multidimensional metabolomic data. Metabolomics 2015, 11, 1029-1034. [CrossRef] [PubMed]

48. Qazi, S.S.; Li, D.; Briens, C.; Berruti, F.; Abou-Zaid, M.M. Antioxidant activity of the lignins derived from Fluidized-Bed Fast Pyrolysis. Molecules 2017, 22, 372. [CrossRef] [PubMed]

Sample Availability: Sample Availability: Not available. 